\title{
How well do children aged 5-7 years recall food eaten at school lunch?
}

\author{
Janet M Warren ${ }^{1, *}$, C Jeya K Henry ${ }^{1}$, M Barbara E Livingstone ${ }^{2}$, Helen J Lightowler ${ }^{1}$, \\ Suzanne M Bradshaw ${ }^{1}$ and Sylvia Perwaiz ${ }^{1}$ \\ ${ }^{1}$ Nutrition and Food Science Group, School of Biological and Molecular Sciences, Oxford Brookes University, \\ Gipsy Lane Campus, Headington, Oxford OX3 OBP, UK: ${ }^{2}$ Northern Ireland Centre Diet and Health, \\ University of Ulster, Cromore Road, Coleraine, Co. Londonderry, BT52 1SA, UK
}

Submitted 12 November 2001: Accepted 19 March 2002

\begin{abstract}
Objective: This study aimed to determine the accuracy with which children aged 5 to 7 years were able to report the food eaten at a school lunch.

Subjects/setting: Two hundred and three children (103 boys, 100 girls) aged 5-7 years were recruited from three primary schools in Oxford.

Design: Trained investigators made observational records of the school dinner and packed lunch intakes of four or five children per session. Children were interviewed within two hours of finishing the lunchtime meal and asked to provide a free recall of their meal. When the child had completed the recall, non-directive prompts were used to assess if the child was able to remember anything else. Foods recalled were classified as matches (recalled food agreed with observation), omissions (failed to report a food observed) or phantoms (recalled food was not observed).

Results: The percentage of accurate recall was significantly higher $(P<0.01)$ in children eating packed lunch (mean $70 \pm 29 \%$ ) than in children consuming school dinners (mean $58 \pm 27 \%$ ). This difference may have been due to increased familiarity of foods in packed lunches. Leftovers were not readily reported in this age group. Prompts and cues enhanced recall by all children.

Conclusions: This study indicated that there was a wide range in the ability of children aged 5-7 years to recall intake from a packed lunch and/or school dinner. This dietary assessment method is unlikely to be suitable at an individual level. Investigators using dietary recall to estimate food intake in children aged 5-7 years need to be aware of the limitations of this method.
\end{abstract}

Keywords Lunch recall

Children

Dietary assessment
Children are increasingly being targeted in preventive nutrition programmes ${ }^{1-3}$. Dietary interventions form a part of such nutrition programmes. The accurate assessment of dietary intake is thus essential in order to monitor the effectiveness of such programmes. The methodologies for obtaining dietary information in young children must be closely scrutinised in order to select the optimum tool for dietary assessment in this group. Dietary survey work is fraught with potential errors and pitfalls. This is due to a variety of inherent problems such as reliance on memory, lack of honesty in reporting, failure to record habitual intake and non-compliance ${ }^{4-6}$. In children these problems are compounded, since a child's cognitive skills may not be sufficiently developed to permit independent reporting of their own food intake ${ }^{7-9}$.

In the last 10 years progress has been made in understanding the cognitive processes involved in the recall of dietary data by children. These processes have been elucidated and defined by Baranowski and Domel ${ }^{10}$ as attention, retention, retrieval and report. Further work has demonstrated that children employ a number of retrieval mechanisms during a self-report of their dietary intake: visual imagery (appearance of food); usual practice (familiarity with food); behaviour chaining (association with preferred food or favourite activity during a meal or day); and preference (favourite food) ${ }^{11}$. Perceived importance of the foods eaten has also been shown to affect the recall ability of a child ${ }^{12}$.

Early studies indicated that children aged 6 to 10 years might be able to provide reliable dietary information using a recall method ${ }^{13,14}$ and this concurs with more recent reports $^{9,15}$. The ability of children aged 8 years and older to give reports of diet is important, as children are increasingly taking responsibility for their food choice at an earlier age ${ }^{8}$. Therefore, parents may not be very reliable surrogate reporters of their children's food intake, especially for food eaten outside the home ${ }^{16}$. However, parents must still be relied on to provide dietary 
information for younger children and several studies have shown that parents are reliable informants on the diets of pre-school children ${ }^{17-20}$. A potentially problematic group is children in the 5 to 7 year age group. These children are unable to provide a complete dietary report themselves because of cognitive immaturity, and at the same time parents and/or carers do not have total responsibility for their food intake whilst in school.

This study aims to determine the accuracy with which children aged 5 to 7 years are able to report the food eaten at a school lunch. The outcome of this study will have implications for dietary assessment methodology in this age group, which has tended to rely on parental report.

\section{Methods}

\section{Subjects}

Two hundred and three children (103 boys, 100 girls) aged 5-7 years were recruited from three primary schools in Oxford. The schools were all within a one-mile radius of Oxford Brookes University and served a similar catchment area. All of the children were taking part in a large-scale health promotion study that targeted all children in Years 1 and 2. Parental consent was given for approximately $45 \%$ of the eligible children to join the main study. There was a bias towards children from the high socio-economic classes, with approximately half the children coming from this group. Ethical approval for the study was obtained from The Applied and Qualitative Research Ethics Committee of the Oxford Radcliffe NHS Trust, Headington, Oxford.

\section{Observations}

All investigators were dietitians/nutritionists who had received prior training on the observation procedures by the principal investigator. The format of the observations was adapted from the methods described by Domel et al. ${ }^{11}$ and Bollella et $a .^{21}$. Prior to lunch it had been established which children ate a packed lunch (PL) brought from home and which children ate a school dinner (SD) (Table 1). Each investigator was responsible for monitoring the lunch intakes of four or five children per observation period. The investigators were known to the children through their involvement in the health promotion study and therefore their presence in the canteen was perceived as an extension of this study. Consequently the children were not aware that their lunch intakes were being observed and that subsequent recall of their intakes was planned.

Table 1 Number (\%) of children who ate packed lunch and school dinner

\begin{tabular}{lcc}
\hline Class (age) & Packed lunch & School dinner \\
\hline Year 1 (5-6 years) & $91(45)$ & $38(19)$ \\
Year 2 (6-7 years) & $41(20)$ & $33(16)$ \\
\hline
\end{tabular}

For children eating PL, investigators made a covert checklist of the contents of each lunch box in the morning. This was to overcome the difficulties involved with assessing the types of food covered by bags and wrappers. During the observations, progress with eating the various dietary items was recorded using the checklist. Leftovers were noted and, if required, the lunch box was checked again in the afternoon. In all cases, lunch boxes were stored in cloakrooms outside the classroom.

For children eating SD, observers were positioned at the serving point in the canteen or school hall and recorded the content of each child's meal at this initial stage. The investigator then moved to the tables, where progress with the meal was recorded covertly. Any leftover food destined to be discarded was noted. Swapping of food/drinks between children was closely monitored and recorded by all investigators.

\section{Interviews}

An investigator carried out the recall interview with each child within two hours of finishing the lunchtime meal. An interview lasted for approximately 10-15 minutes and all interviews were conducted in the library or another quiet place. First, each child was asked to provide a recall of his/her lunch without any prompting by the investigator. When it was apparent that the child had finished the recall, non-directive prompts were used to assess if the child was able to remember anything else. Questions such as 'Is that everything?' and 'Did you eat anything else?' were used as prompts. Each child was asked specifically about leftovers at the end of the interview. This was omitted in children who were unable to provide any recall of the lunchtime meal. A standardised pro forma (Appendix) for recording all information was used by all interviewers to ensure consistency across investigations.

The foods recalled were classified as matches (observed as eaten and reported as eaten), omissions (observed as eaten but not reported as eaten) or phantoms (not observed eaten but reported as eaten), as described by Baxter et $a l .{ }^{12}$. For each child, additional information was noted, such as the order in which foods had been recalled, if further information had been gained by using prompts and if reports of leftover food were given spontaneously or after prompting. Observations were carried out between December 1999 and September 2000.

\section{Statistical analysis}

Statistical analysis was performed using the Statistical Package for Social Sciences (SPSS 10.0.5; SPSS Inc., Chicago, IL, 1999). Data are presented as frequencies, means and standard deviations. Prior to statistical analysis, the normality of the data was tested using the Kolmogorov-Smirnov statistic with a Lilliefors significance level. The Pearson correlation was used to determine the association between the number of foods served and the number of foods correctly recalled. The Chi 
test was used to assess differences in frequency in selected variables, e.g. omissions of food eaten. Statistical significance was set at $P<0.05$.

\section{Results}

\section{Food items served}

There was no significant difference in the mean number of food items provided by both PL ( $4.9 \pm 1.2$, range $2-8)$ and SD ( $4.9 \pm 0.8$, range $3-7)$. All foods provided in PL and SD were classified and recorded and it should be noted that some meals contained more than one food from the same category (Table 2). A main dish and savoury snack/fried accompaniment were among the most common foods provided; sweet foods were more prevalent in PL. None of the children who ate SD consumed any fruit.

\section{Foods recalled}

The proportion of children in each percentage recall quartile for PL and SD is shown in Fig. 1. This was calculated by dividing the number of foods correctly recalled by the number of foods observed eaten and converting this to a percentage; for example, a child who correctly recalled 3 out of the 4 foods observed eaten would have a percentage recall of $75 \%$ and therefore be in the upper quartile of percentage recall. The mean number of foods observed as eaten and reported by the children was similar for PL $(3.3 \pm 1.4)$ and SD $(2.8 \pm 1.3)$. However, the percentage of accurate recall was significantly higher $(P<0.01)$ in children who ate PL (mean $70 \pm 29 \%)$ compared with those who ate SD (mean $58 \pm 27 \%$ ). A significant proportion $(P<0.001)$ of children eating PL $(70 \%)$ and SD (87\%) omitted at least one food from their recall. The percentage recall in Year 2 children (aged 6-7 years) was significantly better than that of Year 1 children (aged 5-6 years) $(P<0.01)$.

There was a weak association $(r=0.22)$ between the number of foods offered and the number of foods

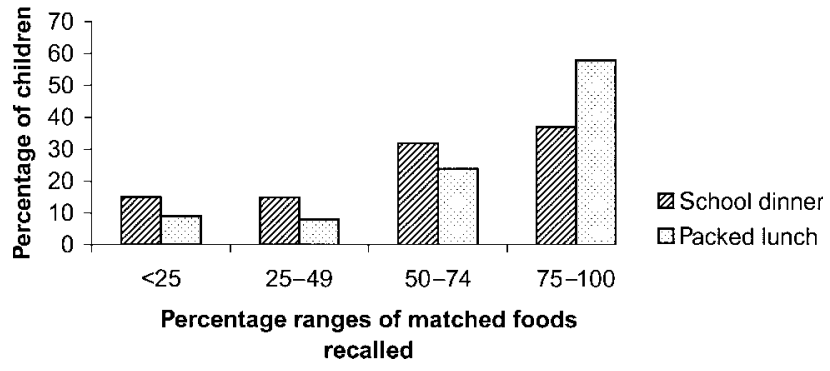

Fig. 1 Distribution of percentage of correct recall in children eating packed lunch and school dinner

correctly recalled (i.e. the recall of foods as eaten) by the packed lunch group (Fig. 2(a)); this association was not apparent in children eating SD (Fig. 2(b)). Figure 2(a) shows that the more foods the children were given for PL, the less likely they were to remember all of them. None of the children given 6 or 7 foods recalled all 6 or 7 foods. Those given 8 foods recalled a maximum of 4 of them. This was similar for SD (Fig. 2(b)) except that fewer children were offered 6 foods or more.

For the majority of children main dishes or drinks were the first items recalled. Forty per cent of children eating PL recalled their main dish first and 37\% recalled their drink first. The figures for children eating SD were $32 \%$ and $39 \%$, respectively. Five per cent or less of the children recalled vegetables, fruit or savoury accompaniments first.

The total percentage recall of each food group is shown in Table 3. This was calculated by dividing the total number of food groups offered by the total number of correct recalls of each food group. For example, 132 main dishes were offered and recorded as eaten in the children eating PL, of which 108 were correctly recalled; therefore the percentage recall for main dishes in packed lunch children was $82 \%$. For PL children main dishes and drinks were the items best recalled while SD children were better at recalling fried accompaniments and main dishes. Vegetables were not well recalled by either group. Recall of sweet foods by children eating SD was also poor.

Table 2 Proportion of packed lunches $(\mathrm{PL})$ and school dinners $(\mathrm{SD})$ containing at least one food item from the food groups and overall breakdown of food items per lunchtime meal

\begin{tabular}{|c|c|c|c|c|c|c|c|c|}
\hline \multirow[b]{2}{*}{ Food type } & \multicolumn{2}{|c|}{$\begin{array}{l}\text { Proportion of } \\
\text { PL containing } \\
\text { each food item } \\
\quad(n=132)\end{array}$} & \multicolumn{2}{|c|}{$\begin{array}{l}\text { Proportion of } \\
\text { SD containing } \\
\text { each food item } \\
\quad(n=71)\end{array}$} & \multicolumn{2}{|c|}{$\begin{array}{l}\text { Total number of } \\
\text { food items in PL } \\
\quad(n=648)\end{array}$} & \multicolumn{2}{|c|}{$\begin{array}{l}\text { Total number of } \\
\text { food items in SD } \\
\quad(n=345)\end{array}$} \\
\hline & $n$ & $\%$ & $n$ & $\%$ & $n$ & $\%$ & $n$ & $\%$ \\
\hline Main dish & 132 & 100 & 71 & 100 & 132 & 20 & 71 & 21 \\
\hline Side dishes & 132 & 100 & 68 & 96 & 133 & 21 & 68 & 20 \\
\hline Sundries & 11 & 8 & 46 & 6 & 11 & 2 & 46 & 13 \\
\hline Vegetable & 11 & 8 & 22 & 3 & 11 & 2 & 22 & 6 \\
\hline Fruit & 62 & 47 & 0 & 0 & 62 & 10 & 0 & 0 \\
\hline Sweet food & 132 & 100 & 71 & 100 & 177 & 27 & 73 & 21 \\
\hline Drink & 122 & 92 & 65 & 92 & 122 & 19 & 65 & 19 \\
\hline
\end{tabular}

Classification: main dish (e.g. sandwich, fish fingers, pizza); side dishes (e.g. potato, rice, crisps, cheese savouries, chips); sundries (e.g. sauce, crackers, gravy); vegetable; fruit; sweet food (pudding, biscuit, yoghurt); drink. 


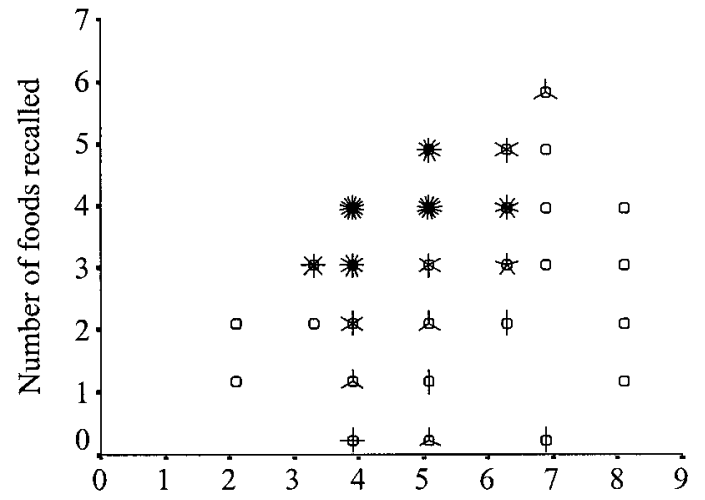

(a)

Number of foods served

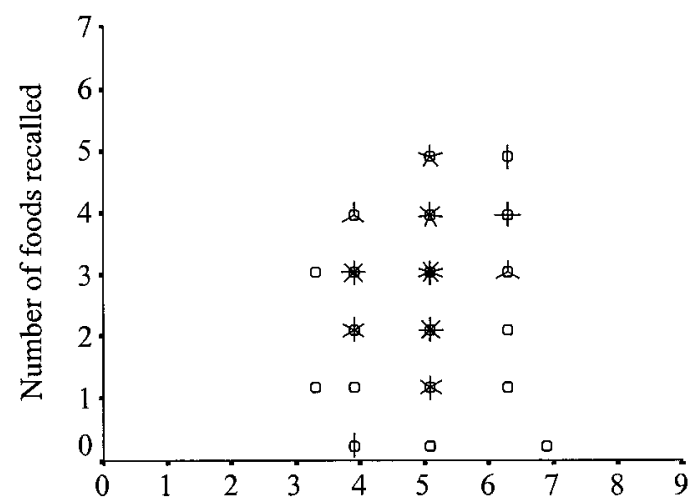

(b)

Number of foods served

Fig. 2 Relationship between number of foods served and recalled as eaten for children eating (a) packed lunch and (b) school dinner. A circle $(O)$ represents a single subject only. Thereafter, each line from a circle represents a data point; e.g. $\phi=2$ subjects, $\downarrow=4$ subjects. The relationship between the number of foods served and recalled is described by the equation $y=$ $0.2565 x+2.044(r=0.22)$ for children eating packed lunch, and the equation $y=0.2752 x+1.427(r=0.16)$ for children eating school dinner

Phantom foods and problems providing food names Phantom foods are foods recalled as eaten but not observed as eaten. There was no significant difference between the mean number of phantom foods reported between groups: $1.4( \pm 0.99$, range $1-5)$ in the PL group and 1.9 ( \pm 0.99 , range $1-3)$ in the SD group. However, PL children were twice as likely as SD children to report phantom foods (Table 4).

Five per cent of children eating PL and 17\% of children eating SD were unable to give the exact name a food (Table 4). Nevertheless, these children gave a good description of the recalled food and, in two cases, also gave the name of an equivalent food. These descriptions were accepted as a correct recall; for example, a triangle with vegetables was a description given for a samosa.
Table 3 Percentage $(n)$ recall for each food group before prompting

\begin{tabular}{lcc}
\hline & \multicolumn{2}{c}{$\%$ recall of each } \\
& food group $(n)$ \\
\cline { 2 - 3 } Food group & $\begin{array}{c}\text { Packed } \\
\text { lunch }\end{array}$ & $\begin{array}{c}\text { School } \\
\text { dinner }\end{array}$ \\
\hline Main dish & $82(108)$ & $68(48)$ \\
Side dishes & $65(86)$ & $74(50)$ \\
Sundries & $0(0)$ & $61(28)$ \\
Vegetable & $45(5)$ & $45(10)$ \\
Fruit & $50(31)$ & $--^{*}$ \\
Sweet food & $60(106)$ & $34(25)$ \\
Drink & $79(96)$ & $55(36)$ \\
Total foods recalled & $70(432)$ & $58(197)$ \\
\hline
\end{tabular}

* No fruit presented at school dinner.

\section{Reporting of leftover foods}

From the cohort of children, leftover food was not observed for $20 \%(n=26)$ of children eating PL and $52 \%$ $(n=37)$ of children eating SD. For the remaining children ( $n=106 \mathrm{PL}, n=34 \mathrm{SD}), 13 \%(n=14)$ of children eating PL and $15 \%(n=5)$ of children eating SD gave a correct report of their leftover food (Table 4).

\section{Use of prompts}

Non-directive prompts such as 'Is that everything?' or 'Did you eat anything else?' were used after the children had finished the recall. Prompting significantly increased $(P<$ $0.001)$ the percentage of foods correctly recalled from $66 \%$ $( \pm 29 \%)$ to $80 \%$ ( $\pm 22 \%$ ). The use of prompts significantly improved recall in both Year 1 and Year 2 children $(P<$ 0.001) although Year 2 children still had a significantly higher recall $(P<0.05)$ overall.

In $\mathrm{PL}$ children prompting significantly increased the mean number of foods recalled from 3 to 4 and the percentage recall from $70 \%$ to $81 \%(P<0.001$ and $P<0.001$, respectively). Similarly, in SD children prompting significantly increased the mean number of foods recalled from 3 to 4 and the percentage recall from $58 \%$ to $79 \%(P<0.001$ and $P<0.001$, respectively $)$. After prompting there was a significant positive correlation ( $r=0.40, P<0.001$ ) between the number of foods offered and the number of foods recalled in children eating PL. In addition, children were prompted about leftover foods. Of the children who had leftover foods, the percentage of children not reporting any leftover foods

Table 4 Percentage $(n)$ of children reporting phantom foods, leftover foods and having problems providing the name of foods

\begin{tabular}{lcccc}
\hline & $\begin{array}{c}\text { Phantom } \\
\text { foods }\end{array}$ & $\begin{array}{c}\text { Problems } \\
\text { providing } \\
\text { name of food }\end{array}$ & $\begin{array}{c}\text { Incomplete } \\
\text { report } \\
\text { of leftover } \\
\text { food }\end{array}$ & $\begin{array}{c}\text { Failure } \\
\text { to report } \\
\text { leftover } \\
\text { food }\end{array}$ \\
\hline $\begin{array}{l}\text { Packed lunch } \\
\text { School dinner }\end{array}$ & $\begin{array}{l}22(29) \\
11(8)\end{array}$ & $\begin{array}{c}5(7) \\
17(12)\end{array}$ & $\begin{array}{c}10(11) \\
9(3)\end{array}$ & $\begin{array}{c}77(81) \\
76(26)\end{array}$ \\
\hline
\end{tabular}


decreased from $77 \%$ to $57 \%$ and from $76 \%$ to $62 \%$ in the PL group and SD group, respectively.

\section{Discussion}

This study set out to investigate the ability of children aged 5-7 years to give an accurate dietary recall of their lunch meal eaten in school. The average percentage accuracy of recall of the number of foods eaten was similar to that reported by Emmons and Hayes ${ }^{14}$ for Grade 1 children (aged 6-7 years). The wide range in accuracy (0-100\%), however, suggests that the data will not be reliable at an individual level. Further work is required to investigate the reliability of such data at a group level. In the present study, recall was higher in children eating PL than in children eating SD. One possible explanation may be an increased familiarity and interest in the foods brought from home compared with those provided in school. As the large majority of children eating packed lunch were Year 1 children (who had a less accurate recall than Year 2 children), the packed lunch/school dinner difference may be underestimated as it was not adjusted for age.

The finding that the children eating both PL and SD who were offered more foods failed to recall all of them is in agreement with previous findings. Meredith et $a l^{13}$ and Baranowski et al. $^{16}$ investigated recall in children who were all eating school meals and found that when children were offered more foods the level of accurate recall decreased.

For both groups the foods recalled first were either the main dish (e.g. sandwiches, fish fingers, shepherd's pie) or beverage (e.g. juice or water). The best recalled foods for packed lunch children were main dishes and drinks, while for school dinner children main dishes and savoury side dishes (potatoes, rice, chips, crisps, cheese savoury snacks) were best remembered. Emmons and Hayes ${ }^{14}$ also found that primary foods (main course foods such as eggs, poultry, meat, fish) were better recalled than secondary foods (such as desserts, starches and accessory foods). Baxter et $a l .{ }^{12}$ noted that the main dish and beverages were the items best remembered by children. In our study children eating SD had their beverages poured for them at varying points of their meal and beverage consumption appeared more incidental in these children than in those eating PL. This is borne out by the fact that beverage consumption was less well remembered by children eating SD than by those eating PL.

Baxter et al. ${ }^{12}$ concluded that salience of food was more important than liking of food in recall, although both were important factors of recall. The recall of the main dish was found to be predictive of the overall accuracy of recall. Results from this study also indicate that the perceived importance of the food was an important factor in recall, as the main dish was the best-remembered food in the packed lunch group and second best in the school dinner group. Sweet foods had a 60\% correct recall and 34\% correct recall in children eating PL and SD, respectively. Assuming that children inherently like sweet foods ${ }^{22}$, this finding suggests that liking of food may not be the most important factor for recall. Although the preference for foods was not tested in this study, the enhanced recall by PL children may be due to an overall higher preference for the foods provided compared with SD children.

Leftover food was omitted or inadequately reported by all children. This may be due to a total disregard of leftovers or, possibly, leftovers may be perceived as undesirable by some children's families and therefore were not reported. Social desirability has been seen to influence the report of young children ${ }^{23}$ but not others ${ }^{16}$. No pattern emerged as to successful predictors of reporting of leftover food. This has implications for any nutritional analysis of a dietary recall in this age group.

The prompts employed in this study were purposefully non-directive. Cues and prompts have been shown to be vital to gain maximum recall and specific pathways of storage and retrieval of information have been elucidated $^{10-12}$. However, a full understanding of the cognitive processes involved in food recall is essential to ensure that cues do not overburden or confuse ${ }^{9}$. Consequently a child should first be allowed a free recall of a meal with no interruptions, followed by recapping and non-directive prompts $^{5}$ (as in this study). To elicit the best recall in children, probing about the main dish, preference and familiarity of the foods should then follow. The findings from this research confirm that these may be important facets of the recall process. Finally, leftover food should be specifically asked about at the end of the recall process.

No pattern was observed in the reporting of phantom foods, since foods from all groups were reported but not eaten, although PL children were twice as likely to report phantom foods. Where children struggled to provide the exact name of a food, but had a clear memory of the food eaten and were able to provide an adequate description of the food, this was accepted as a correct recall. This may be a potential source of error in other studies where investigator observations are unlikely to have occurred and therefore descriptions of food would be more difficult to interpret. More children had difficulty giving the exact names of food in the SD group than in the PL group (17\% compared with 5\%). This may be attributed to the possible influence that PL children may have over the food offered, as previously mentioned. A limited knowledge of food and its preparation is a recognised problem in the dietary assessment of children ${ }^{14,24}$, and this may be reduced if children are familiar with the foods eaten. Allowing children to draw and/or describe the food or showing them pictures may be useful in alleviating this problem; however, this warrants further investigation to ensure that these methods do not influence and lead children's responses.

A limitation of the present study is that it is not representative of the population, as half of this cohort of 
children was from the higher socio-economic classes and none of the schools served a deprived population. This may affect the generalisability of the results of this study.

In conclusion, this study has shown that there is a wide range in the ability of children aged 5-7 years to give a recall of a packed lunch and/or school dinner, which makes it an unsuitable dietary assessment method at an individual level. It may be of adequate accuracy at a group level, but further research is required to ascertain this. This would have implications on dietary recall in this age group, which has tended to rely solely on parental report. Prompts and cues enhance recall and leftovers are not readily reported in this age group. Children taking packed lunches appeared to have a better recall possibly due to increased familiarity of foods.

\section{Recommendations and future work}

A summary of the recommendations and suggestions for future work that emerged from this study are appended below.

- Children aged 5-7 years should be allowed a 'free' recall of foods eaten without interruption.

- Prompts should be employed at the end of the recall.

- Prompts should concentrate on the child's recall of the main dish and their familiarity with and preference for the foods recalled.

- Prompts should not overburden a child.

- Side dishes, fruit, vegetables and sweet foods may need specific inquiry.

- Inquiry about leftover food should be made in a nondirective manner.

- The effects of: (1) a longer time lag between the meal and recall and (2) environmental factors on the accuracy of recall, need to be established.

- The estimation of portion sizes (beyond the remit of this study), using aids appropriate to the cognitive development of the child, needs to be assessed.

\section{Acknowledgements}

This study formed part of a project funded by the Food Standards Agency. We would like to thank the children who took part in this study and the schools for their co-operation with the study.

\section{References}

1 Dietz WH. Prevention: it all starts with the children. Appetite 1998; 31(3): 413-6.

2 Hill JO, Trowbridge FL. Childhood obesity: future directions and research priorities. Pediatrics 1998; 101(3): 570-4.

3 Schmitz MKH, Jeffery RW. Public health interventions for the prevention and treatment of obesity. Med. Clin. N. Am. 2000; 84(2): 491-512, viii.

4 Bingham S, Nelson M, Paul A, Haraldsdottir J, Loken EB, van
Staveren WA. Methods for data collection at an individual level. In: Cameron ME, van Staveren WA, eds. Manual on Methodology for Food Consumption Studies, 1st ed. New York: Oxford University Press, 1988; 53-106.

5 Medlin C, Skinner JD. Individual dietary intake methodology: a 50-year review of progress. J. Am. Diet. Assoc. 1988; 88(10): $1250-7$.

6 Thompson FE, Byers T. Dietary assessment resource manual. J. Nutr. 1994; 124(11 Suppl.): 2245S-317S.

7 Haraldsdottir J, Hermansen B. Repeated 24-H recalls with young schoolchildren - a feasible alternative to dietary history from parents. Eur. J. Clin. Nutr. 1995; 49(10): 729-39.

8 Rockett HR, Colditz GA. Assessing diets of children and adolescents. Am. J. Clin. Nutr. 1997; 65(4 Suppl.): 1116S-22S.

9 Livingstone MB, Robson PJ. Measurement of dietary intake in children. Proc. Nutr. Soc. 2000; 59(2): 279-93.

10 Baranowski T, Domel SB. A cognitive model of children's reporting of food-intake. Am. J. Clin. Nutr. 1994; 59(1): S212-7.

11 Domel SB, Thompson WO, Baranowski T, Smith AF. How children remember what they have eaten. J. Am. Diet. Assoc. 1994; 94(11): 1267-72.

12 Baxter SD, Thompson WO, Davis HC, Litaker MS. Children's dietary recalls: the salience of entree and liking for foods on accuracy and order of reporting. Nutrition 1999; 15(11-12): 848-53.

13 Meredith A, Matthews A, Zickerfoose M, Weagley E, Wayave M, Brown EG. How well do school children recall what they have eaten? J. Am. Diet. Assoc. 1951; 27: 749-51.

14 Emmons L, Hayes M. Accuracy of 24-hour recalls in young children. J. Am. Diet. Assoc. 1973; 62: 409-15.

15 McPherson RS, Hoelscher DM, Alexander M, Scanlon KS, Serdula MK. Dietary assessment methods among schoolaged children: validity and reliability. Prev. Med. 2000; 31(2): S11-33.

16 Baranowski T, Dworkin R, Henske JC, Clearman DR, Dunn JK, Nader PR. The accuracy of children's self-reports of diet: Family Health Project. J. Am. Diet. Assoc. 1986; 86(10): 1381-5.

17 Basch CE, Shea S, Arliss R, Contento IR, Rips J, Gutin B, et al. Validation of mothers reports of dietary-intake by 4-year-old to 7-year-old children. Am. J. Public Health 1990; 80(11): $1314-7$.

18 Eck LH, Klesges RC, Hanson CL. Recall of a child's intake from one meal: are parents accurate? J. Am. Diet. Assoc. 1989; 89(6): 784-9.

19 Klesges RC, Klesges LM, Brown G, Frank GC. Validation of the 24-hour dietary recall in preschool-children. J. Am. Diet. Assoc. 1987; 87(10): 1383-5.

20 Johnson RK, Driscoll P, Goran MI. Comparison of multiplepass 24-hour recall estimates of energy intake with total energy expenditure determined by the doubly labelled water method in young children. J. Am. Diet. Assoc. 1996; 96(11): 1140-4

21 Bollella MC, Spark A, Boccia LA, Nicklas TA, Pittman BP, Williams CL. Nutrient intake of Head Start children: home vs. school. J. Am. Coll. Nutr. 1999; 18(2): 108-14.

22 Birch LL. Development of food preferences. Ann. Rev. Nutr. 1999; 19: 41-62.

23 Van Horn LV, Gernhofer N, Moag-Stahlberg A, Farris R, Hartmuller G, Lasser VI, et al. Dietary assessment in children using electronic methods: telephones and tape recorders. J. Am. Diet. Assoc. 1990; 90(3): 412-6.

24 Samuelson G. An epidemiological study of child health and nutrition in a northern Swedish county II. Methodological study of the recall technique. Nutr. Metab. 1970; 12(6): $321-40$. 


\section{Appendix - Recall of school lunch}

Name

Class

Code

1) Ask the child did they have a packed lunch or a school dinner

a) packed lunch

b) school dinner

2) Ask the child what they had to eat and drink. Do not give any prompts. Write down the items in the exact order of recall.

Items recalled

3) Prompt the child and see if anything else was consumed (e.g. did you have anything to drink, did you eat anything else with...?)

Items recalled
4) Did the child mention not finishing any item? Yes/No

5) If yes what items were mentioned as being unfinished?

Items unfinished

6) If no to number 4 prompt the child and ask if any item was unfinished.

Items unfinished (recalled)

Thank you 